\title{
LA FENOMENOLOGÍA DE LA PERCEPCIÓN EN SPINOZA
}

\author{
Zachary Hugo \\ Saint Xavier University, Chicago, USA \\ hugo@sxu.edu
}

\begin{abstract}
RESUMEN / ABSTRACT
En este artículo desafío la aseveración sostenida por Peden (2014) y Brandt (2011) de que la filosofía de Spinoza es esencialmente incompatible con ciertas posiciones fundamentales de la fenomenología. Contra eso, sostengo que lo que Spinoza llama la imaginación se asemeja a la percepción en la fenomenología de Merleau-Ponty. Se justifica esa tesis a partir de una lectura semiótico-hermenéutica de la teoría de la imaginación spinozista, la cual permite ver ciertas semejanzas entre las epistemologías de percepción entre estos respectivos filósofos. A la vez, al destacar las convergencias entre Spinoza y Merleau-Ponty, se ponen de relieve las divergencias entre el cartesianismo y la fenomenología, y surge la posibilidad de una lectura novedosa de la fenomenología desde una perspectiva spinozista.
\end{abstract}

Palabras clave: Spinoza, Merleau-Ponty, semiótica, fenomenología, imaginación, percepción.

\section{Spinoza's Phenomenology of Perception}

In this article, I challenge Peden (2014) and Brandt's (2011) claims that Spinoza's philosophy is essentially at odds with certain basic phenomenological positions. Against this, I argue that Spinoza's theory of imagination is akin to Merleau-Ponty's phenomenology of perception. I justify this thesis by developing a semiotic-hermeneutic interpretation of Spinoza's theory of imagination which makes it possible to see certain similarities between these respective philosophers' epistemologies of perception. By highlighting the convergences between Spinoza and Merleau-Ponty, the divergences between Cartesianism and phenomenology come to the fore along with the possibility of a novel reading of phenomenology from a Spinozist perspective.

KEYWORDS: Spinoza, Merleau-Ponty, semiotics, phenomenology, imagination, perception. 


\section{Introducción}

RA La filosofía de Spinoza ha sido interpretada y apropiada de muchas maneras distintas y por un grupo muy diverso de filósofos, tanto de la tradición analítica como de un corriente racionalista de la tradición continental ${ }^{1}$. A la vez, hay una carencia conspicua de la influencia de Spinoza -ya sea explícita o implícita- en la fenomenología del siglo XX². De hecho, en su libro Spinoza Contra Phenomenology (2014), Knox Peden busca demostrar que la recepción francesa posguerra de Spinoza juega un papel importante en el eventual rechazo a la fenomenología de la segunda mitad del siglo. Si bien el libro de Peden es una obra de la historia intelectual y no se ahonda en las sutilezas de la filosofía de Spinoza ni de la fenomenología ${ }^{3}$, el autor no deja de sostener que la apreciación de Spinoza por parte de ciertos filósofos es una respuesta crítica al supuesto cartesianismo de la fenomenología ${ }^{4}$. Desde otra perspectiva, el semiotista Per Aage Brandt ha argumentado que "la fenomenología es imposible desde la perspectiva de Spinoza" y que Spinoza es "el padre de la filosofía analítica" mientras que Descartes es "el padre de la fenomenología" (Brandt 2011: 33, 28).

1 Brandt (2011) destaca ciertos vínculos entre Spinoza y el positivismo lógico de Carnap, Frege, Russell, y el Wittgenstein de la Tractatus; el conductismo/empirismo de J.B. Watson, B.F. Skinner; y la semiótica de C.S. Peirce. Peden (2014), por su parte, rastrea la influencia de Spinoza en el racionalismo continental de Cavaillès, Gueroult, Deleuze, y Althusser. Cabe mencionar aquí también el trabajo de Damasio (2003), que busca relacionar la filosofía de Spinoza con la neurociencia contemporánea.

2 La excepción es Paul Ricoeur, quien ha abiertamente expresado la influencia de Spinoza en su hermenéutica más tardía, por ejemplo, en Soi-même comme un autre (1990). Aun en su primera obra, Le voluntaire et l'involuntaire (1950), se pueden notar las influencias de Spinoza en su concepción del 'consentimiento'.

3 Peden mismo admite que su libro no pretende ofrecer una "comprehensive account of twentieth-century French Spinoza scholarship" (ibíd.: 6s.).

$4 \quad$ Vale explicitar que tal tesis presupone varios puntos discutibles: (i) que Descartes y Spinoza se oponen filosóficamente de una manera radical; (ii) que la filosofía de Descartes es un fundamento esencial de la fenomenología; es decir, que la fenomenología realmente es cartesiana; y (iii) que es válida la interpretación por parte de tales spinozistas franceses tanto de las filosofías de Spinoza y Descartes como de la fenomenología. En este artículo, no abordaré ni (i) ni (iii), ya que mi argumento no depende de la (in)validez de estas suposiciones. En cuanto al (ii), hay varios trabajos sobre la relación entre Descartes y la fenomenología al menos de Husserl (véase, esp., MacDonald 2000). En cuanto a la afinidad entre Descartes y la fenomenología husserliana, se suele apuntar a la primacía epistemológica (y posiblemente metafísica) de la conciencia (res cogitans) frente al conocimiento del mundo externo/trascendente (res extensa), por ejemplo, en (Husserl 1977: $\S \S 46-49)$. Para una crítica a esta interpretación de Husserl, véase (Taguchi 2017). Sartre parece refrendar esa doctrina cartesiana en L'imaginaire (1986), pues a lo inmanente a la conciencia denomina "lo cierto" y a lo trascendente "lo probable". Para un análisis de la relación entre las filosofías de Descartes y Merleau-Ponty, la cual es más compleja aun, véase (de Saint Aubert 2005). 
En el presente artículo pretendo desafiar y problematizar esta imagen de la relación entre la fenomenología y la filosofía de Spinoza. Mas, en vez de examinar críticamente la recepción de Spinoza por parte de los racionalistas continentales estudiados en el libro de Peden o los filósofos analíticos mencionados por Brandt, este artículo busca ofrecer una interpretación de Spinoza que converge con ciertas tesis fundamentales de la fenomenología. En particular, sostengo que la presunta oposición entre Spinoza y la fenomenología pierde su fuerza cuando se destacan ciertos aspectos semióticos y cuasihermenéuticos en la obra de Spinoza. Es decir, si bien hay ciertas diferencias patentes entre la filosofía de Spinoza y la fenomenología, el impacto de tales divergencias es menos contundente cuando se considera la filosofía de Spinoza desde una perspectiva semiótico-hermenéutica. Un posible resultado importante de mi tesis, si mi argumento tiene éxito, es que se debe dejar de interpretar la fenomenología como una mera prolongación de la tradición cartesiana, en particular en cuanto a sus preocupaciones epistemológicas, pues también tiene sus raíces spinozistas y anticartesianas. Más aún, pretendo criticar la intención misma de buscar las raíces filosóficas de la división entre la fenomenología y otras filosofías críticas a ella porque sostengo que tal división no es, en rigor, una división filosóficamente defendible.

Como interlocutor fenomenológico con Spinoza se considerará a Maurice Merleau-Ponty por dos razones. Primero, Merleau-Ponty fue un contemporáneo de varios de los filósofos de la renaissance spinoziste en Francia, es decir, de los filósofos que supuestamente recurren a Spinoza para luchar contra el supuesto cartesianismo de la fenomenología. Si hay convergencias relevantes entre la fenomenología merleaupontyana y la filosofía de Spinoza, entonces no será tan evidente que Spinoza sea un antecedente solamente para los soi-disant spinozistas franceses en esta época. Segundo, según una interpretación muy popular pero bastante simplista e incorrecta, mientras que Husserl nunca dejó de ser cartesiano en aspectos importantes, Heidegger salió de esa tradición ultraintelectualista, enfatizando la primacía del comportamiento práctico por sobre la epistemología y definiendo el sujeto como Dasein y ser-en-el-mundo en vez del ego trascendental separado del mundo. Si bien esta caricaturización de ambos fenomenólogos alemanes ha tenido una influencia fuerte en la recepción francesa de la fenomenología en general, Merleau-Ponty fue un buen lector de Husserl y, con algunas excepciones, no fue víctima de esa imagen tan simplista e incorrecta de Husserl y Heidegger ${ }^{5}$. Por tanto, Merleau-Ponty es un representante bastante ecuánime no solamente de la fenomenología husserliana y su recepción en Francia, sino también de su reformulación por parte de Heidegger.

El artículo se organiza de la siguiente manera. En primer lugar, esbozaré una interpretación semiótica de Spinoza. Para ello, esta investigación se concentrará en la distinción que hace Spinoza entre los tres tipos de conocimiento, con más atención prestada a los primeros dos tipos. Especialmente importante aquí serán los conceptos (2002). 
de la imaginación, las nociones comunes, y la corrección de errores perceptualesimaginativos. En segundo lugar, se destacarán algunas convergencias entre las conclusiones extraídas de esta primera sección y la fenomenología presentada por Merleau-Ponty en su discurso, Le primat de la perception et ses conséquences philosophiques (1989). En tercer lugar, las posibles críticas a estas convergencias se analizarán, así como se abordarán las posibilidades de una fenomenología spinozista. Vale decir que, dada la inmensidad de las obras de los filósofos mencionados aquí, de ninguna manera este artículo pretende abordar la relación entre ellos de una manera exhaustiva. Más bien, este artículo sirve como base para más indagaciones sobre los posibles paralelos entre las nociones de imaginación, percepción, afectividad y racionalidad tanto en Spinoza como en la fenomenología del siglo XX.

\section{La semiótica de Spinoza}

Para comenzar, vale definir muy brevemente el concepto de la semiótica, al menos con respecto a su uso en este artículo. En su sentido más amplio, la semiótica es el estudio de la estructura de los signos y la significación (Chandler 2007: 2) ${ }^{6}$. En este sentido general y amplio, la semiótica comprende tres "dimensiones": (i) la relación entre signos (la sintáctica); (ii) la referencia a objetos significados (la semántica); (iii) y la relación entre el signo y su intérprete (la pragmática) (Pelc 1997: 429s). Descrito así, la semiótica no parece diferir mucho de la lingüística; y en efecto, la semiótica nace explícitamente como disciplina propia con la lingüística estructuralista de Ferdinand de Saussure en su Cours de linguistique générale (1995) y la lógica y teoría de signos de Charles Sanders Peirce (2011) al comienzo del siglo XX $X^{7}$. No obstante, si bien el lenguaje provee un modelo concreto para estudiar las tres dimensiones de semiosis, la noción de 'signo' en la semiótica es más amplia, incluyendo otros tipos de signo: e.g., arquitectura, diseño, artes culinarias y los gestos corporales ${ }^{8}$. Es a partir de ese sentido amplio y abarcador de la semiótica que pretendo desarrollar una lectura semiótica de Spinoza.

La interpretación semiótica de Spinoza, aunque no tan trabajada, tiene un precedente. Lorenzo Vinciguerra $(2005 ; 2012)$ ha avanzado esta lectura a partir de la teoría de imaginación y percepción sensible de Spinoza. En particular, se concentra Vinciguerra en las nociones de la huella (vestigia), el signo y la imagen y concluye que, para Spinoza, la interpretación de los signos se asemeja a ciertas tendencias hermenéuticas en la semiótica -lo que corresponde mayormente a la dimensión (iii)

$6 \quad$ Véase Chandler (2007: Introduction) para un resumen más extenso de las varias definiciones de la "semiótica".

7 Mientras que Saussure enfatiza el carácter social de la función del signo, cuyo estudio se suele denominar la semiología, Peirce se concentra en el carácter formal y lógico del signo. Las diferencias entre sus respectivas teorías y métodos no nos concierne aquí. Pelc (1997: 429) apunta a Roman Jakobson a este respecto. 
de la semiosis, i.e., la pragmática. En vista a eso, Vinciguerra afirma que, además de aportar "a la formulación de reglas racionales para interpretar un documento o texto desde un punto de vista filológico e histórico", Spinoza "concibe la imaginación misma como un proceso de la interpretación de signos, como una semiosis natural, universal e infinito, en el cual todos los individuos en cuanto modos participan, cada uno según su manera particular de ser, rastreado [traced] y marcado por otros cuerpos" (2012: 142). Es decir, el significado de un signo es relativo a la particularidad de cada intérprete.

A la vez, Vinciguerra nos recuerda que la relatividad de interpretaciones no llega a ser un "subjetivismo hermenéutico". Al contrario, Spinoza nos ofrece un "'realismo" radical", puesto que los signos interpretados expresan "la esencia de Dios mediante un cuerpo que tiene el poder de afectar y ser afectado, un poder compartido por todos los individuos" (ibid.: 133) . Brandt también ha defendido una interpretación semiótica de Spinoza y llega a la conclusión de que la interpretación de signos no conlleva un subjetivismo, sino que se asemeja a una tendencia en ciertos positivistas del siglo XX (Brandt 2011: 33). En particular, los filósofos que auspician la idea de un mundo ordenado lógicamente cuyo sentido no depende de o cambia según las interpretaciones o descubrimientos de cada sujeto hallan en Spinoza un espíritu afín. Es decir, el sentido (el orden) de lo interpretado es algo objetivo; el conocedor debe espejar la lógica-delmundo adecuadamente, siguiendo el orden de la naturaleza.

De ahí que tengamos dos aspectos de la lectura semiótica de Spinoza: por un lado, la imaginación se define como la interpretación de signos en un sentido amplio (incluyendo, e.g., la percepción sensible), y, por otro lado, cada interpretación está sujeta a normas objetivas estipuladas por una suerte de lógica-del-mundo cuya validez es independiente de la interpretación de cada individuo. En vista de eso, la pregunta importante es ¿cómo se pasa desde la interpretación de signos relativista al conocimiento más y más adecuado de la realidad objetiva? Para enfrentar esta pregunta, es preciso entrar en más detalle en la noción de la imaginación en Spinoza.

Primero, Spinoza explícitamente define la imaginación como la cognición a partir de los signos (cognitio ex signis) (EIIp40s2), la cual involucra la ideación de relaciones entre imágenes ${ }^{10}$. Para Spinoza, las imágenes son las afecciones (affectiones) que surgen en un cuerpo cuando este interactúe con otro cuerpo (EIIp16c2, EIIp17s). Las ideas de tales afecciones del cuerpo son imaginaciones (imaginationes). Es decir, imaginamos cuando pensamos en dichas afecciones. Es importante notar que Spinoza dice claramente que estas afecciones, o imágenes, no "reproducen las figuras de las cosas" (EIIp17s). Más bien, las ideas de las afecciones "nos presentan los cuerpos exteriores

9 Asimismo, nos recuerda que, para Spinoza, la imaginación no es una facultad de la mente humana. Tal antropocentrismo es ajeno a la filosofía de Spinoza, pues para ésta el humano no es una sustancia, sino solo uno de los infinitos modos de Dios, o la Naturaleza (Vinciguerra 2012: 136).

10 La abreviatura "E" corresponde a la Ética de Spinoza (2000) y sigue la manera tradicional de citar esta obra. 
como presentes" (ibid.). Estas ideas de las afecciones, las imágenes, Spinoza las define como "ideas confusas e inadecuadas" y niega que puedan involucrar algún conocimiento adecuado sobre un cuerpo externo (EIIp28, p29), pues solamente indican el estado del cuerpo afectado, no el afectante (EIIp16c2). Este primer tipo de conocimiento, la imaginación, forma nociones generales a partir de cosas singulares que percibimos "de forma mutilada, confusa, o sin orden al entendimiento" a partir de la "experiencia vaga" y los signos $(\text { ibid. })^{11}$. Entonces, las imágenes parecieran ser, parafraseando a Sartre, epistémicamente pobre (Sartre 1986: 10); es decir, no ofrecerían ningún elemento que pueda conducir al conocimiento adecuado de otros cuerpos.

Ahora bien, para Spinoza, la idea (el significado interpretado) que se forma a partir de un signo no es igual para cada persona. Spinoza da el siguiente ejemplo para ilustrar este punto:

Pues un soldado, por ejemplo, al ver en la arena las huellas de un caballo, pasará al instante del pensamiento del caballo al del jinete, y de éste al de la guerra, etc.; un campesino, en cambio, del pensamiento del caballo pasará al del arado, del campo, etc. Y así, cada cual, según ha acostumbrado a unir y concatenar las imágenes de las cosas de tal o cual manera, pasará de un pensamiento a este o a aquel otro (Spinoza, EIIp18s).

Si las huellas en la arena conllevan un significado diferente para cada persona según el orden que se haya dado a sus imágenes, un determinado signo no se adecúa a un significado de una manera consistente y predecible. Dado eso, parecería que la imaginación no está regida por ninguna condición de verdad, i.e., el objeto real en el mundo. Por lo mismo, la imaginación no es una condición suficiente para el conocimiento de la verdad.

Sin embargo, Spinoza llama la imaginación el primer tipo de conocimiento (EIIp40s2), y, por tanto, se supondría que incluye alguna noción de vericondicionalidad o normatividad epistémica. Pero eso se ve difícil de sustanciar, puesto que, según Spinoza, "las imaginaciones del alma, consideradas en sí mismas, no contienen error alguno, es decir, que el alma no yerra por imaginar" (EIIp17s). Más bien, el error tiene que ver con la falta de -i.e., la ignorancia de- una idea que excluiría la existencia de las cosas imaginadas como presentes (ibid.). Es decir, la imaginación, por más que no ofrezca, por sí sola, ningún conocimiento de la verdad, tampoco es el error, aunque sea la única 'fuente' del error (EIIp41). Más bien, erramos cuando tomamos nuestras

11 Para un análisis más detallado del conocimiento del primer tipo, véase, Curley (1973), quien destaca la evolución de la definición de la imaginación desde la primera obra de Spinoza, el Breve Tratado hasta su Ética. En la primera obra, Spinoza define la imaginación como conocimiento "ex auditu", término que Curley traduce como "from report" para no privilegiar la audición y también para destacar la importancia de la autoridad del reportador (reporter) (Curley 1973: 30, 32). En la Ética, Spinoza lo define como conocimiento a partir de los signos (ex signis); no obstante, Curley afirma que el mismo sentido se da en ambas definiciones: es un conocimiento validado meramente por la autoridad que lo entrega. 
imaginaciones como si fueran representaciones verdaderas de la realidad ${ }^{12}$. Spinoza toma el ejemplo de nuestra distancia al sol. Si creemos que el sol está a solamente doscientos metros de nosotros, ya que así se nos presenta, erramos. Pero, al saber que la distancia entre nosotros y el sol está a más de seiscientos diámetros de la tierra desde nosotros, seguiremos viendo el sol como si estuviera a solamente doscientos metros de nosotros, pero sabremos que así no es en realidad (EIIp35s) ${ }^{13}$.

Cabe destacar que Spinoza sigue la larga tradición de las teorías de correspondencia con respecto a la verdad. En cuanto a la propiedad extrínseca de tal correspondencia, Spinoza invoca lo usual: "La idea verdadera debe concordar con su objeto ideado [Idea vera debet cum suo ideato convenire]" (EIa6). En cuanto a la propiedad intrínseca, Spinoza recurre a las nociones de claridad y distinción para resolver los problemas normalmente asociados a la teoría de correspondencia de la verdad. Como sostiene Dan Nesher (1994), la claridad se refiere a "la articulación semántica (significativo [meaningful]) de la idea y la distinción es el resultado inferencial (interpretacional) de ella" (Nesher 1994: 144). Pero, en la medida en que las imágenes son ideas oscuras y confusas, solo se puede encontrar tal claridad y distinción en una idea que excluya la existencia de lo que tales imágenes representan como siendo presentes. Esas ideas se forman a partir de las 'nociones comunes' (EIIp37), las cuales representan la realidad de una manera más adecuada.

Si la realidad se representa más adecuadamente a partir del conocimiento de las nociones comunes, la pregunta importante es entonces, ¿cómo se forman las nociones comunes a partir de la imaginación? Dicho de otro modo, puesto que la imaginación no deja de valer como una forma o nivel de conocimiento para Spinoza, ¿cómo se genera el conocimiento más adecuado a partir del conocimiento inadecuado provisto por la imaginación? Como hemos visto, el imaginar no es el errar sin más. Solo podemos errar cuando tomamos una cierta actitud o posición frente a la (ir)realidad de lo representado por la imaginación. Pero eso no excluye que sigamos ignorantes del hecho de que lo que tomamos como una representación verdadera de la realidad es 'en realidad' una falsa representación. Es decir, falta un criterio para distinguir entre una representación falsa (imaginación tomada como si fuera verdadera) y el conocimiento de tal representación como siendo falsa. Tal criterio valdría cómo lo que descubre la falsedad de una imaginación, y eso permitiría entender cómo se puede corregir una representación falsa.

12 Bennett (2001: cápitulo 5) critica la teoría de falsedad en Spinoza: a saber, Spinoza no puede dar cuenta de la "misrepresentation." Garrett (2017), por su parte, acepta ciertos elementos de la crítica de Bennett pero muestra una posible solución a tales críticas en Spinoza.

13 Este ejemplo se asemeja a varios casos de ilusiones visuales estudiados en la filosofía de la percepción. Por ejemplo, en el caso de la famosa ilusión de Müller-Lyer es posible que uno vea una de las líneas como siendo más larga que la otra y, simultáneamente, que sepa que las dos líneas tienen el mismo tamaño. En términos de la filosofía de la percepción de William Fish, Spinoza permite la posibilidad de usar el gorro epistemológico y el gorro fenoménico a la vez (Fish 2010: 54-58). 
Aquí se trata, sobre todo, del origen de la verdad, pues la corrección de una falsedad no podría pasar sin una idea de lo no falso, es decir, lo verdadero. Para Spinoza, el conocimiento de la verdad es lo que pertenece a las ideas adecuadas. La adecuación de estas ideas se debe al conocimiento de ciertas propiedades comunes tanto al cuerpo afectado como al cuerpo afectante, i.e., las nociones comunes. La idea de una afección involucra en parte tanto la naturaleza del cuerpo humano como la de los cuerpos externos (EIIp16). La idea de las propiedades comunes entre los diversos cuerpos involucrados en una afección es adecuada porque lo es en Dios, o la Naturaleza. Dios tiene la idea de un cuerpo humano y las ideas de las afecciones (EIIp7c). Y el conocimiento de estas nociones comunes, adecuado en Dios, es también adecuado en nosotros. Es decir, se trata de un cambio de perspectiva.

Es preciso destacar que el conocimiento a partir de nociones comunes no depende de las imágenes ni de los signos: veritas nullo egeat signo (TIE, sección 36). Spinoza sostiene que la imaginación no ayuda en la formación de nociones epistémicamente válidas. Aun en el caso de una concatenación de imágenes del mismo objeto, las cuales están acompañadas siempre con el mismo signo, la imaginación solo crearía una idea complejamente confusa, no más adecuada. Por ejemplo, al percibir una manzana muchas veces y escuchar la palabra "apple" en la presencia de ese objeto, se formará un vínculo muy fuerte entre el objeto y la palabra inglesa. Pero este vínculo se basa en una idea altamente confusa (EII40s1). Es decir, no se llega a las nociones comunes por la adición de imágenes semejantes. Más bien, solamente la verdad, en cuanto norma o medida, puede generar el conocimiento adecuado a partir de la confusión provista por la imaginación.

Mas, si necesitamos una idea adecuada para saber que nuestras ideas son inadecuadas -i.e., para distinguir entre lo verdadero y lo falso-, ¿acaso no necesitaríamos otra idea verdadera para saber que tenemos una idea verdadera en el primer lugar, y así ad infinitum? Formalmente expresado: sea A una idea inadecuada y sea B una idea adecuada que sirve para darse cuenta de lo falso de A mediante su comparación con B. Para saber que B es realmente verdadera y no otra idea inadecuada B', necesitamos otra idea adecuada, C, para distinguir entre B y B'. Y así seguiría el regreso infinito.

La respuesta que Spinoza propone a esta objeción tiene una importancia particular para nuestra investigación. Aunque él sí responde a este problema en la Ética (EIIp43), también proporciona una explicación en su Tratado de la emendación del intelecto (TIE) durante su discusión sobre el problema de método. En esta obra incompleta, Spinoza resuelve este problema con referencia a la noción de 'herramientas' intelectuales. En breve, el mismo problema de un regreso infinito aparece al reflexionar sobre la invención de las herramientas. Cito:

[...] para forjar el hierro requerimos un martillo, y para tener un martillo es necesario que lo confeccionemos. Y, a fin de lograr lo anterior requerimos de otro martillo y otras herramientas. $<$ Ahora bien $>$, para tener estas últimas se requieren otras herramientas, y así al infinito. Y de este modo sería vano el esfuerzo de quien quisiera demostrar que los hombres no pueden forjar el hierro. Pero del mismo modo en que en un comienzo los hombres pudieron hacer ciertas cosas 
muy fáciles con instrumentos innatos, aunque laboriosa e imperfectamente, y una vez que fueron fabricadas, confeccionaron otras más difíciles con menos esfuerzo y de modo más perfecto. Y así, avanzando gradualmente a partir de los trabajos más simples a los instrumentos, y de los instrumentos a otros trabajos e instrumentos, llegaron a tal punto, que fabricaron muchas cosas difíciles con poco esfuerzo (Spinoza 2008: $\S \S 30-31$ ).

Spinoza sostiene que lo mismo sucede con el intelecto del humano. Nacimos con ciertos instrumentos innatos, y con ellos el intelecto logra crear instrumentos intelectuales para sí mismo, los cuales sirven para crear otras herramientas, etc. La verdad, conocida a partir del segundo (y tercer) tipo del conocimiento, no requiere más justificación que la verdad misma. Y para arribar a cualquier verdad, basta con desarrollar las herramientas del intelecto ${ }^{14}$.

En conclusión, una lectura semiótica de Spinoza conlleva las siguientes aseveraciones. Primero, la relación entre los signos (las imágenes) y sus significados depende de las experiencias que la persona ha tenido. Es decir, el soldado y el campesino perciben, o interpretan, las huellas de un caballo según sus experiencias con caballos. Este acto de interpretación no conduce a la verdad, pero solo es una causa del error si se toma como un juicio sobre cómo son las cosas en realidad. Segundo, este "cómo son las cosas en la realidad" es algo que entrega el segundo (y tercero) tipo de conocimiento a partir de las nociones comunes que se forman sobre las propiedades de las cosas. Este conocimiento no piensa mediante imágenes sino a partir de una perspectiva más abarcadora -y últimamente a partir de la perspectiva divina. Tercero, cuando se compara nuestra imaginación de las cosas con este conocimiento adecuado de ellas, estamos conscientes del error en cuanto tal. Sin embargo, seguimos percibiendo las imágenes como antes, solamente sin incurrir en error, ya que conocemos la verdad.

Entonces, para Spinoza, signos tienen referencia a diversos significados, pero el sentido verdadero del mundo no aparece en ellos mismos sino en una captación más "objetiva" de las propiedades comunes en los cuerpos involucrados. Esta captación será auto-evidente a la hora de evaluar su validez. Es decir, sabremos que nuestra idea es adecuada porque la verdad es su propia norma, según Spinoza. Entonces, si bien la imaginación admite una suerte de relativismo de interpretación, para salir de la ignorancia no basta con el mero interpretar. Para llegar a la verdad, tenemos que

14 Si bien tal explicación responde al problema del regreso infinito, no deja muy claro cómo los instrumentos innatos del intelecto se desarrollan. Es decir, no es muy evidente cómo una noción de la verdad 'nace' de módulos o instrumentos intelectuales primitivos preepistemológicos. En su psicología de desarrollo, Lev Vygotsky recurre a esta noción del instrumento intelectual para enfrentar este tipo de problema (véase Robbins 2001: 95ss.). Si bien Vygotsky muestra cómo tal desarrollo ocurre, no enfrenta el problema más al fondo: a saber, ¿cómo surgen nociones normativas como la verdad y falsedad en la naturaleza (véase, de Caro 2010). Garrett (2017) ofrece una posible solución a este problema, apelando a la noción de conato en Spinoza. 
comparar estas interpretaciones con un conocimiento más adecuado de lo interpretado. Una vez comparada con un conocimiento adecuado, la verdad será auto-evidente.

\section{Spinoza y la fenomenología: una reevaluación}

Se suele considerar que la fenomenología es una prolongación del cartesianismo ${ }^{15}$. Prima facie, y desde una lectura muy precaria, la duda metodológica de Descartes se asemeja a la epojé de Husserl. Sin embargo, la comparación es bastante superficial en la medida en que la epojé no pone en duda la existencia del mundo, sino que neutraliza la posición o tesis general, cuya forma por defecto es la proto-doxa frente a la existencia de lo intencionado ${ }^{16}$. La duda es, para Husserl, un modo de la posición (Setzung) ${ }^{17}$, y la epojé es la neutralización completa de tal tendencia dóxica. Esta posicionalidad neutral frente a lo trascendente hace manifiesto el mismo mundo, pero desde otra perspectiva: lo trascendente aparece en lo inmanente como nóema. Y desde esta perspectiva, deviene posible investigar las condiciones de la posibilidad de la constitución de la realidad objetiva.

Ahora bien, pese a las diferencias entre el método de Husserl y el de Descartes, parece muy difícil avanzar la tesis de que la fenomenología husserliana y sus reformulaciones posteriores en otros fenomenólogos recurrieran a Spinoza para formar su propio método. Pero eso no es mi tesis. Más modestamente, solo pretendo mostrar que nuestra lectura semiótica de Spinoza permite hacer puente entre su teoría de imaginación y conocimiento, por un lado, y ciertos elementos de la fenomenología de la percepción presentada por Merleau-Ponty. En particular, me concentraré en el discurso breve, La primat de la perception, el cual pretende ser un resumen de su obra más grande, La phénoménologie de la perception.

Algunos estudios ya han buscado destacar las convergencias entre la filosofía de Merleau-Ponty y la de Spinoza ${ }^{18}$. Homero Santiago (2004) aborda la posibilidad de tales convergencias tomando la obra más tardía de Merleau-Ponty, Le visible et l'invisible, destacando las semejanzas entre las ontologías respectivas de ambos filósofos. En particular, Santiago afirma que, "a pesar de la cantidad, no despreciable, de divergencias" entre Spinoza y Merleau-Ponty, se manifiestan sus convergencias al considerar que ambos piensan "en el todo, en el nexo y en el entrecruzamiento de sus partes, en su expresividad esencial" y buscan investigar "la continuidad entre nosotros y el mundo y el ser" (Santiago 2004: 25).

15 Para un argumento a este efecto, véase Romano (2012). Para una crítica a la lectura de Romano, véase Staiti (2015).

16 Véase Husserl (1977: §§30-32).

17 Véase Husserl (1939: §21).

18 El rechazo de Merleau-Ponty a Spinoza se explora en Fóti (2013: 98-99). 
Henry Pietersma (2001), por su parte, busca los pasajes en los cuales MerleauPonty -explícita o implícitamente- alude a Spinoza. Allí, Pietersma encuentra en $L a$ phénoménologie de la perception varias referencias a Spinoza, y también afirma que Le visible et le invisible "presenta una posición que muestra una cierta semejanza notable [striking] a Spinoza" (Pietersma 1988: 91). Sin embargo, Pietersma sugiere que la divergencia más importante entre los dos filósofos atañe a sus filosofías de percepción. Para Spinoza, "la percepción es un poder que debe ser criticado por el poder superior del intelecto"; mientras que para Merleau-Ponty, "la percepción es un poder que se critica a sí mismo y resuelve sus propios problemas del conocimiento cuando éstos surjan" (ibid. 92). Si bien hay cierta razón en lo que dice Pietersma aquí, valdría revisitar la relación entre Spinoza y Merleau-Ponty bajo la luz de nuestra lectura semiótica de este primero.

Para Merleau-Ponty, "el mundo percibido sería la fundación siempre presupuesta por toda racionalidad, todo valor y toda existencia. Esta tesis [Une conception de ce genre] no destruye ni la racionalidad ni lo absoluto. Más bien, busca bajar éstos a la tierra" (Merleau-Ponty 1989: 43) ${ }^{19}$. Para entender su punto aquí, es preciso preguntar por la relación entre la percepción y la racionalidad en Merleau-Ponty. Para ello, me valdría de una cita larga en que Merleau-Ponty destaca la diferencia entre la experiencia perceptiva de un objeto y nuestro conocimiento geométrico del mismo objeto:

$\mathrm{Si}$, por ejemplo, miro un cubo, conociendo la estructura del cubo tal como se define en la geometría, puedo anticipar las percepciones que este cubo me dará mientras me muevo alrededor de él. Bajo esta hipótesis, conocería los lados no vistos como la consecuencia necesaria de una cierta ley del desarrollo de mi percepción. Pero si advierto a la percepción misma, no puedo interpretarla de esta manera porque este análisis puede formularse de la siguiente manera: Es verdadero que la lámpara tiene una espalda, que el cubo tiene otro lado. Pero esta fórmula, "Es verdadero", no corresponde a lo que se me da en la percepción. La percepción no me proporciona verdades como la geometría, sino presencias. Capto el lado no visto como presente, y no afirmo que la espalda de la lámpara existe en el mismo sentido que digo que la solución de un problema existe. El lado escondido es presente en su propia manera. Está en mi alrededor (Il est dans mon voisinage) (Merleau-Ponty 1989, p. 45).

Es decir, para Merleau-Ponty, la percepción parece medirse contra otras condiciones que no se reduzcan a normas epistémicas o aléticas como en la geometría y otras ciencias (nociones comunes, en los términos de Spinoza). A la vez, no es que la geometría invalide la experiencia perceptiva, incluso cuando haya una disparidad entre estas, ni viceversa. Para utilizar los términos de W. Sellars ${ }^{20}$, la imagen manifiesta de la percepción y la imagen científica solamente son incompatibles cuando se evalúa la primera según las normas de la segunda, o viceversa ${ }^{21}$. Mientras que la percepción se rige por leyes

19 Todas referencias a la obra de Merleau-Ponty son mis traducciones.

20 Véase Sellars (1963).

21 No pretendo sostener que Sellars estaría de acuerdo con esta aseveración. 
de perspectividad y orientación, la geometría abstrae de la perspectividad para aislar proposiciones verdades que no son dependientes de la posición espacial de cada cual.

Según la sección anterior, la imaginación es, para Spinoza, una estructura semiótica mediante la cual se interpretan signos para arribar a sus significados que son diversos en cada humano. Es decir, la imaginación, para Spinoza, es relativa siempre a la perspectiva del percipiente. Además, la imaginación no nos da verdades ni falsedades. Si bien es la única posible fuente de falsedades, la imaginación en sí no es error, pues no se mide contra normas epistémicas o aléticas en primer lugar. El error entra en juega a la hora de juzgar o tomar una posición dóxica frente a la realidad de lo imaginado. Y, aun después de lograr este conocimiento más adecuado, mi experiencia sensible normalmente no cambia, como en el ejemplo del sol en Spinoza (o, más recientemente, de las líneas de Müller-Lyer). En resumen, para Spinoza, la imaginación ofrece el primer contacto con el mundo, un contacto todavía inocente e ingenuo, y las ciencias (establecidas por nociones comunes) abstrae de tal naïveté para establecer un conocimiento no basado en las perspectividad de cada uno.

Según esta descripción de la teoría de imaginación de Spinoza, ya podemos ver ciertas semejanzas importantes con la fenomenología de Merleau-Ponty. Según este último, la percepción representa el primer contacto con el mundo. Además, el carácter de este contacto perceptual es más fácil de observar en los niños (Merleau-Ponty 2010), los que sufren de una patología (e.g., el caso de "Schneider" en Merleau-Ponty 1945), y el arte de Paul Cézanne (Merleau-Ponty 1964b). Es decir, los que carecen de la razón o que buscan la expresión prerracional del mundo visible estarían en una relación imaginativa con el mundo según Merleau-Ponty, y ciertamente según Spinoza. De hecho, según la lectura de Merleau-Ponty provista por Trevor Perri (2013: §4), hay un elemento cuasi-imaginario en toda percepción. Un artista como Cézanne, además, puede recordarnos cómo debería aparecer el mundo sin la superposición de la imagen científica sobre la imagen manifiesta, es decir, nos recuerda de este primer contacto prerracional: "Nosotros, olvidando las apariencias viscosas y equívocas, atravesamos ellas llegando directamente a [go through them straight to] las cosas que presentan. El pintor recaptura y hace visible [converts into visible objects] aquello que, sin él, seguiría atrapado [walled up] en la distinta vida de cada conciencia: la vibración de las apariencias la cual es la cuna de las cosas" (citado en Perri 2013: 85).

Cabe destacar que, para Merleau-Ponty, la primacía de la percepción no implica una separación completa del mundo científico regido por normas epistémicas. Más bien, la percepción es justamente lo que nos entrega las condiciones para formar ideas más objetivas. Es decir, que la percepción sea primaria significa que "la experiencia de la percepción es nuestra presencia en el momento cuando las cosas, las verdades y los valores se constituyen para nosotros; que la percepción es un logos naciente; que nos enseña, afuera de todo dogmatismo, las verdaderas condiciones de la objetividad misma; que nos llama a la tarea del conocimiento y de la acción" (Merleau-Ponty 1989: 67). Siguiendo la tesis de Husserl, Merleau-Ponty dirá que tal objetividad no es sino 
la intersubjetividad. Las nociones comunes, en los términos de Spinoza, se forman socialmente según una perspectiva fenomenológicamente ${ }^{22}$.

En conclusión, valdría decir que la primacía de la percepción quizá no se traduciría en una primacía de la imaginación en Spinoza. Pero esto no significa que la imaginación no sea primaria de ninguna manera. Su descripción de las herramientas intelectuales y del desarrollo del sentido en el humano atestigua que, de hecho, en el camino hacia el conocimiento pleno de la naturaleza empezamos casi siempre con las imágenes y la interpretación relativista de signos. Sin embargo, para Spinoza, debemos ${ }^{23}$ escapar de la esclavitud de la imaginación; afirmación que se expone en Libros IV y V de la Ética. En este sentido, la imaginación no solamente puede conducirnos a errores epistémicos sino a una condición de pura pasividad afectiva, de la cual no podemos escapar sin recurrir a la razón y la ciencia intuitiva ${ }^{24}$. Se podría afirmar, en vista de eso, que la imaginación es una condición necesaria (pero obviamente insuficiente) del conocimiento más adecuado: sin imaginación no habría posibilidad de error, y sin error no habría motivo de salir de la esclavitud producida por la imaginación, volviéndose más y más activo con respecto a los afectos.

\section{Conclusión: ¿es posible una fenomenología spinozista?}

Huelga decir que hay ciertas diferencias muy obvias entre Spinoza y la fenomenología en general. Primero, Spinoza sostiene una posición metafísica determinista y necesarianista, la cual no es compatible con la posición fenomenológica, puesto que la conciencia no es parte del mundo causal sino su condición de inteligibilidad. La totalidad e inmanencia absoluta de Dios, $o$ la Naturaleza, entendida como un sistema de causas, cabría bajo una mera región ontológica (de la materialidad) según la fenomenología. La causalidad es una noción metafísica, una relación entre cuerpos para explicar sus interacciones nomológicas. La epojé pone en suspensión tales presuposiciones metafísicas para describir cómo el sentido de la causalidad se constituye. La determinación causal aplica solamente a la región ontológica de la cosa (Ding), pero no a objetos de otra índole, e.g., objetos ideales (números, sentidos) o sentidos culturales ${ }^{25}$. La conciencia también tiene sus reglas y leyes, pero se estructuran no solamente según la modalidad

22 Cabe destacar que Vygotsky interpreta a Spinoza de esa manera también. La socialización es el modo del desarrollo de los instrumentos intelectuales innatos (Robbins 2001: Capítulo 4).

23 El tipo de normatividad presente en ese "deber" es complicado de exponer. Sobre este tema, véase Lagrée (2002).

24 El tema de los afectos, hasta ahora no desarrollado en este artículo, ciertamente tiene su lugar en la fenomenología. De hecho, Husserl explícitamente dice que su teoría de motivación pasiva tiene un precedente en Spinoza (y Hobbes) (Husserl 1952: 222).

25 Husserl describe la constitución de materialidad y causalidad en (Husserl 1952: §§15-18). 
de necesidad, sino también de posibilidad y probabilidad (posibilidad motivada), así abriendo el paso para una suerte de libertad en el mundo ${ }^{26}$.

Si bien tal divergencia no es menor en su importancia, el propósito de esta investigación era solo mostrar que una lectura semiótica de la teoría de la imaginación en Spinoza -la cual destaca la particularidad y perspectividad de la percepción de modos finitos-se asemeja a la percepción como la define Merleau-Ponty. Además, la noción spinozista de la corrección de la imaginación por la razón no está completamente contraria a la fenomenología, como alude Pietersma. Según Merleau-Ponty, el conocimiento científico-racional puede corregir las percepciones, pero solamente en vista a una norma epistémica basada en la imagen científica. Pero antes de tal evaluación epistémica, la percepción se rige por otras normas ${ }^{27}$. En Spinoza, la imaginación es semejante a este tipo de percepción prerracional. Obviamente, para Spinoza (y para cualquier racionalista moderno), la perspectividad de la imaginación tiene una carga negativa: nos enceguece de la realidad vista desde la perspectiva de Dios. Este enceguecer tiene además una carga ética: la imaginación nos puede esclavizar y solamente la razón y la ciencia intuitiva nos liberan.

Además de este punto, que no tiene vínculo explícito en Merleau-Ponty ${ }^{28}$, la filosofía de la imaginación/percepción de Spinoza ciertamente no parece estar en contra de la fenomenología. Esto es, en parte, la tesis de esta investigación. Pero cabría destacar un punto más. Supuestamente los $\operatorname{críticos}^{29}$ a la fenomenología ven en ella una influencia cartesiana. Sin embargo, Descartes no provee una teoría de la percepción parecida a la de Merleau-Ponty. De hecho, la filosofía de la percepción de Spinoza parece estar más cercana a la de Merleau-Ponty que lo es la de Descartes. MerleauPonty mismo crítica la filosofía de percepción de Descartes refiriéndose a su famosa descripción de la percepción de la cera: "Para Descartes -y esta idea ha mantenido el dominio sobre la tradición filosófica francesa por mucho tiempo- la percepción no es más que los principios confusos del conocimiento científico. La relación entre la percepción y el conocimiento científico es aquella de la apariencia a la realidad" (Merleau-Ponty 2004: 42).

Esta evaluación de Descartes también se podría hacer de Spinoza. No obstante, y como este artículo ha tratado de mostrar, para Spinoza la imaginación no incluye necesariamente un juicio sobre la realidad, sino la manera que el mundo afecta a un modo singular, e.g., un percipiente. Para Descartes, la percepción es un juicio desde

26 Para un análisis de las modalidades en Husserl, véase Zhok (2016) y Belussi (1990).

27 Véase Merleau-Ponty (1945: 349): "La distance de moi à l'objet n'est pas une grandeur qui crôit ou décroît, mais une tension qui oscille autour d'une norme." Para un tratamiento de este pasaje en Merleau-Ponty, véase: Kelly (2010). Para una discusión sobre la normatividad de la percepción en general, véase Doyon y Breyer (2015).

28 Cabe mencionar que eso sí se podría encontrar en Husserl (véase, Bernet 1979).

29 Tengo en cuenta aquí, especialmente, a los filósofos mencionados en el libro de Peden (2014). 
el comienzo y esto lo conduce a su duda metodológica (es un juicio dudable). Para Spinoza, la imaginación es la manera en que un sujeto percipiente da sentido a ciertos signos en el mundo. Es una semiótica que trae consigo un sentido, y este sentido ni es verdadero ni falso a menos que se enjuicie sobre él.

En conclusión, se ha de preguntar si Spinoza no es un anti-fenomenólogo, ¿es posible decir que el spinozismo podría ser fenomenológico, o viceversa? La respuesta a esta pregunta tiene implicaciones para cómo entendemos tanto la fenomenología como la filosofía de Spinoza. Si bien la tendencia naturalista de Spinoza no es fácilmente compatible con la fenomenología clásicamente entendida, la posibilidad de una fenomenología naturalizada forma una parte muy importante de la discusión actual (Cf. Petitot, 1999; Zahavi, 2004, 2010; Carel y Meacham 2013). Segundo, uno de los aspectos más importantes de la filosofía de Spinoza, algo no trabajado en este ensayo, es su teoría sobre los afectos. A ese respecto, la fenomenología de la afectividad en Husserl ofrece un posible puente con Spinoza, algo que Husserl mismo parece reconocer ${ }^{30}$.

Finalmente, la idea de la objetividad en Spinoza podría entenderse fenomenológicamente si se diera cuenta del proceso de transitar desde la imaginación a las nociones comunes y a la ciencia intuitiva de una manera genética. Es decir, la cultivación de conocimiento para Spinoza tiene que ver con la ampliación de la perspectiva singular (personal) a una perspectiva más objetiva. Eventualmente esta perspectiva debe llegar a la de Dios, $o$ la Naturaleza. Pero, al mostrar como este proceso no es "personal" sino "interpersonal" e incluso "político" se podría formar una teoría de la objetividad como una misión para la intersubjetividad. El conatus del mundo sería el desarrollo del conocimiento sobre el mundo y eso es un proceso intersubjetivo, no individual. Dicho de otro modo, la fenomenología ofrece, además de un contenido filosófico, un método -la fenomenología genética- para investigar el desarrollo de la razón no solo en el sujeto individual, sino también como un proceso regido por normas intersubjetivas.

\section{Referencias bibliográficas}

Belussi, Felix (1990), Die modaltheoretischen Grundlagen der Husserlschen Phänomenologie. München/Freiburg: Verlag Karl Alber.

Bennett, Jonathan (2001), Learning from Six Philosophers. Oxford: Clarendon Press.

$30 \quad$ Véase (Husserl 1952: 222). Para las lecciones sobre la filosofía de Spinoza por parte de Husserl, véase (Husserl 2012: 424-434). Cabe destacar que, según Husserl, la razón no corresponde solamente al conocimiento teórico-dóxico, y tanto la afectividad como la praxis juegan roles cruciales en el desarrollo de la razón en su sentido más pleno. Para un análisis exhaustivo de este punto, véase Walton (2017). Para una discusión de la relación entre la percepción y la razón en Husserl, véase Hugo (2017). Cabe mencionar que las ideas expresadas en esa publicación de 2017 son más recientes que las ideas expresadas en la presente investigación, pues el presente artículo fue aceptado en 2016. 
Bernet, Rudolf (1979), "Perception as a Teleological Process of Cognition", The Teleologies in Husserlian Phenomenology, pp. 119-132. Dordrecht: Springer.

Brandt, Per Aage (2011), "The Enminded Body. Spinoza, Descartes, and the Philosophy of Cognition-A Critical Note", Chinese Semiotic Studies 5(1): 2641.

de Caro, Mario y David Macarthur (2010), Naturalism and normativity. NY: Columbia University Press.

Carel, Havi y Darian Meacham, eds. (2013), Phenomenology and Naturalism: Examining the Relationship between Human Experience and Nature. Cambridge: Cambridge University Press.

Chandler, Daniel (2007), Semiotics: The Basics. London: Routledge.

Curley, Edwin (1973), "Experience in Spinoza's Theory of Knowledge", Spinoza, a collection of critical essays, ed. M. Grene, Anchor, pp. 25-59.

Damasio, Antonio (2003), Looking for Spinoza: Joy, sorrow, and the feeling brain. Houghton Mifflin Harcourt.

Doyon, Maxime y Thiemo Breyer (2015), Normativity in Perception. New York: Palgrave Macmillan.

Fish, William (2010), Philosophy of perception: a contemporary introduction. New York: Routledge.

Fóti, Véronique (2013), Tracing expression in Merleau-Ponty: Aesthetics, philosophy of biology, and ontology. Northwestern University Press.

Garrett, Don (2017), "Representation, Misrepresentation, and Error in Spinoza's Philosophy of Mind", en Michael Della Rocca, ed., The Oxford Handbook of Spinoza. Oxford University Press.

Hugo, Zachary John (2017), "Horizon, Modality, and Reason: Another Look at Husserl and the Normativity of Perception", Études Phénoménologiques Phenomenological Studies 1: 65-93.

Husserl, Edmund (1939), Erfahrung und Urteil. Untersuchungen zur Genealogie der Logik, ed. Ludwig Landgrebe. Hamburg: Meiner.

(1952), Ideen zu einer reinen Phänomenologie und phänomenologischen Philosophie. Zweites Buch: Phänomenologische Untersuchungen zur Konstitution. Edited by Marly Biemel. The Hague: Martinus Nijhoff (Hua 4).

(1977), Ideen zu einer reinen Phänomenologie und phänomenologischen Philosophie. Erstes Buch: Allgemeine Einführung in die reine Phänomenologie, 1. Halbband: Text der 1.-3. Auflage - Nachdruck. Edited by Karl Schuhmann. The Hague: Martinus Nijhoff (Hua 3/I).

(2012), Einleitung in die Philosophie. Vorlesungen 1916-1920, ed., Hanne Jacobs. Dordrecht: Springer (HuaMat 9).

Kelly, Sean (2010), "The Normative Nature of Perceptual Experience", en Bence Nanay, Perceiving the World. Oxford University Press, pp. 146-159.

Lagrée, Jacqueline (2002), Spinoza et la norme. Presses Universitaires FrancComtoises. 
MacDonald, Paul (2000), Descartes and Husserl the philosophical project of radical beginnings. Albany, N.Y.: State University of New York Press.

Merleau-Ponty, Maurice (1964), Le visible et l'invisible. Paris: Gallimard.

(1945), Phénoménologie de la perception. Gallimard Paris.

(1964), Sense and non-sense. Northwestern University Press.

(1989), Le primat de la perception et ses conséquences philosophiques; précédé de Projet de travail sur la nature de la perception (1933) et La nature de la perception (1934). Grenoble: Cynara.

(2004), The World of Perception. Cambridge University Press.

(2010), Child Psychology and Pedagogy: The Sorbonne Lectures 19491952. Northwestern University Press.

Nesher, Dan (1994), "Spinoza's Theory of Truth", en Hunter, Graeme, and David Savan. Spinoza: the enduring questions. Toronto: University of Toronto Press.

Peden, Knox (2014), Spinoza Contra Phenomenology: French Rationalism from Cavaillès to Deleuze. Stanford University Press.

Peirce, C.S. (2011), "Logic as Semiotic: The Theory of Signs", en Peirce, C.S, Justus Buchler, ed., Philosophical Writings of Peirce; pp. 98-119.

Pelc, J. (1997), "Semantics and Semiotics", en Dalla Chiara, Maria Luisa, Kees Doets, Daniele Mundici, and Johan van Benthem, eds., Structures and Norms in Science: Volume Two of the Tenth International Congress of Logic, Methodology and Philosophy of Science. Florence, August 1995. Vol. 260, pp. 429-431. Springer Science \& Business Media.

Perri, Trevor (2013), "Image and Ontology in Merleau-Ponty", Continental Philosophy Review, Volume 46, Issue 1, pp. 75-97.

Petitot, Jean, Francisco Varela, y Bernardo Pachoud (1999), Naturalizing phenomenology: Issues in contemporary phenomenology and cognitive science. Stanford University Press.

Pietersma, Henry (2001), "Merleau-Ponty and Spinoza", Spinoza: Critical Assessments / Edited by Genevieve Lloyd.

Romano, Claude (2012), "Must phenomenology remain Cartesian?", Continental Philosophy Review 45: 425-445.

Ricœur, Paul (1988), Le Volontaire et l'involontaire. Paris: Aubier.

(1990), Soi-même comme un autre. Paris: Seuil.

Robbins, Dorothy (2001), Vygotsky's Psychology-Philosophy: A Metaphor for Language Theory and Learning. Kluwer: Springer.

de Saint Aubert, Emmanuel (2005), Le scénario cartésien: recherches sur la formation et la cohérence de l'intention philosophique de Merleau-Ponty. Vrin.

Santiago, Homero (2004), "Espinosa e Merleau-Ponty: convergências?” Trans/Form/ Ação 27(1), 19-26. 
Sartre, Jean-Paul (1986), L’imaginaire: psychologie phénoménologique de l'imagination. Paris: Gallimard.

de Saussure, Ferdinand (1995), Cours de linguistique générale. Otto Harrassowitz Verlag.

Sellars, Wilfrid (1963), Science, Perception and Reality. California: Ridgeview Publishing Company.

Spinoza, Baruch (1925), Spinoza Opera, vols. I -V., ed. por Carl Gebhardt. Heidelberg: Carl Winters.

(2000), Ética demostrada según el orden geométrico, trad. Atilano Domínguez. Madrid: Trotta.

(2008), Tratado de la reforma del entendimiento y de la vía con la que se dirige del mejor modo al verdadero conocimiento de las cosas, trads. Boris Eremiev y Luis Placencia. Buenos Aires: Colihue.

Staiti, Andrea (2015), “On Husserl's Alleged Cartesianism and Conjunctivism: A Critical Reply to Claude Romano", Husserl Studies 31: 123-141.

Taguchi, Shigeru (2017), "Annihilation of the World? Husserl's Rehabilitation of Reality", en Walton, Roberto; Shigeru Taguchi and Roberto Rubio, eds., Perception, Affectivity, and Volition in Husserl's Phenomenology. Dordrecht: Springer, 163-177.

Toadvine, Ted y Lester Embree (2002), Merleau-Ponty's Reading of Husserl. Dordrecht: Springer.

Vinciguerra, Lorenzo (2005), Spinoza et le signe: la genèse de l'imagination. Vrin.

(2012), "Mark, Image, Sign: A Semiotic Approach to Spinoza", European Journal of Philosophy 20(1): 130-144.

Walton, Roberto (2017), "Horizonality and Legitimation in Perception, Affectivity, and Volition", en Walton, Roberto; Shigeru Taguchi and Roberto Rubio, eds., Perception, Affectivity, and Volition in Husserl's Phenomenology. Dordrecht: Springer, 3-20.

Zahavi, Dan (2004), "Phenomenology and the project of naturalization", Phenomenology and the cognitive sciences 3(4): 331-347.

(2010), Naturalized phenomenology. Handbook of phenomenology and cognitive science. Dordrecht: Springer, 2-19.

Zhok, Andrea (2016), "Possibility and Consciousness in Husserl's Thought," Husserl Studies 32 (3): 213-235. 